\title{
Energies of Excited States of Doubly Ionized Molecules by Means of Auger Electron Spectroscopy
}

\author{
Part I. Electronic States of $\mathrm{N}_{2}{ }^{2+*}, * *$ \\ D. Stalherm $\dagger$, B. Cleff, H. Hillig, and W. Mehlhorn \\ Institute of Nuclear Physics, University of Münster, Germany \\ (Z. Naturforsch. 24 a, 1728-1733 [1969] ; received 29 August 1969)
}

\begin{abstract}
A new method, Auger electron spectroscopy, is applied to the study of excited states of doubly ionized molecules. The energies of Auger electrons determine directly the vertical energies of doubly ionized states, because the single Auger process leaves the molecule in a state of double ionization. We have investigated the states of $\mathrm{N}_{2}{ }^{2+}$ via the $\mathrm{K}$ Auger spectrum of $\mathrm{N}_{2}$. The ionization in the $\mathrm{K}$ shell was caused by electron impact. The $\mathrm{K}$ Auger electrons, analyzed by means of an electrostatic cylindrical mirror analyzer, gave direct evidence for the following states: $\mathrm{x}^{1} \sum_{\mathrm{g}^{+}}$, $\mathrm{A}^{\prime \prime}{ }^{3} \Sigma_{\mathrm{u}}{ }^{+}, \mathrm{A}^{3} \Pi_{\mathrm{g}}, \mathrm{c}^{1} \Pi_{\mathrm{g}}, \mathrm{d}^{1} \Sigma_{\mathrm{u}^{+}}$, and $\mathrm{e}^{1} \Sigma_{\mathrm{g}}{ }^{+}$. Their energies have been measured and are listed below. Also the energy required to ionize $\mathrm{N}_{2}$ twofold in the $\left(\sigma_{\mathrm{g}} 2 \mathrm{~s}\right)$ orbital has been determined to be $(96.5 \pm 1.0) \mathrm{eV}$. Due to the instrumental half width of about $0.6 \mathrm{eV}$ no vibrational structure could be detected.
\end{abstract}

There exists only little experimental information on electronic and vibrational states of doubly ionized molecules. This is due to the fact that one encounters greater difficulties when the experimental methods used so far to determine these data for neutral and singly ionized molecules are applied in the study of doubly ionized molecules. These methods are absorption and emission spectroscopy, electron impact spectroscopy ${ }^{1}$, photoionization ${ }^{2}$, and photoelectron spectroscopy ${ }^{3}$. In the case of $\mathrm{N}_{2}$ only the appearance potential of the ground state of $\mathrm{N}_{2}{ }^{2+}$ and the energy of the excited state $\mathrm{d}^{1} \Sigma_{\mathrm{u}}{ }^{+}$are known. The former has been measured by DORMAN and MORRIsoN ${ }^{4}$ by electron impact spectroscopy and the latter by CARROLL ${ }^{5,6}$ by uv emission spectroscopy.

In this paper it will be shown that Auger electron spectroscopy is particularly well suited to determine the states of doubly ionized molecules. A molecule which has undergone a single Auger process will be

Reprint requests to Doz. Dr. W. MehlhorN, Institut für Kernphysik der Universität Münster, D-4400 Münster (Westf.), Tibusstr. 7-15.

* This research was supported by the Deutsche Forschungsgemeinschaft.

* Part of this work was presented at the meeting of the German Physical Society in Heidelberg, March 10-15, 1969. Verhandl. DPG (VI) 4, 350 [1969].

$\dagger$ Now at Bergbau-Forschung G.m.b.H., Essen-Kray, Germany.

1 J. D. Craggs and H. S. W. Massey, Encyclopedia of Physics (editor S. FLÜGGE), vol. XXXVII/1, Springer-Verlag, Berlin-Göttingen-Heidelberg 1959. left normally ${ }^{7}$ in a state of double ionization. In the following section the method will be discussed with $\mathrm{N}_{2}$ as an example. After a short description of the apparatus used in this experiment, the $\mathrm{K}$ Auger spectrum is critically analyzed. The various lines of the Auger spectrum are assigned to definite states of $\mathrm{N}_{2}{ }^{2+}$ by comparison with the potential energy curves of the $\mathrm{N}_{2}{ }^{2+}$ molecular ion which have been calculated by the method of HuRLey and MASLEN ${ }^{8}$ and Hurley ${ }^{9}$.

\section{Method}

The electron configuration of the ground state of the $\mathrm{N}_{2}$ molecule is given by

$$
\operatorname{KK}\left(\sigma_{\mathrm{g}} 2 \mathrm{~s}\right)^{2}\left(\sigma_{\mathrm{u}} 2 \mathrm{~s}\right)^{2}\left(\pi_{\mathrm{u}} 2 \mathrm{p}\right)^{4}\left(\sigma_{\mathrm{g}} 2 \mathrm{p}\right)^{2},{ }^{1} \Sigma_{\mathrm{g}}{ }^{+} .
$$

After the $\mathrm{N}_{2}$ molecule has been singly ionized in the $\mathrm{K}$ shell of one of its atoms (this will be written as $\mathrm{N}_{2}{ }^{\mathrm{K}+}$ ) an Auger process will follow with dominating

2 G. L.WeIsSLER, Encyclopedia of Physics (editor S. FlüGGE), vol. XXI, Springer-Verlag, Berlin-Göttingen-Heidelberg 1956.

3 M. I. Al Jaboury and D. W. Turner, J. Chem. Soc. 7, 5141 [1963].

${ }^{4}$ F. H. Dorman and J. D. Morrison, J. Chem. Phys. 35, 575 [1961].

5 P. K. Carroll, Can. J. Phys. 36, 1585 [1958].

6 P. K. Carroll and A. C. Hurley, J. Chem. Phys. 35, 2247 [1961].

7 T. A. Carlson and M. O. Krause, Phys. Rev. Letters 17, 1079 [1966].

8 A. C. Hurley and V. W. Maslen, J. Chem. Phys. 34, 1919 [1961].

9 A. C. Hurley, J. Mol. Spectr. 9, 18 [1962]. 
probability ${ }^{10}$. One electron of the configuration $\left(\sigma_{\mathrm{g}} 2 \mathrm{~s}\right)^{2}\left(\sigma_{\mathrm{u}} 2 \mathrm{~s}\right)^{2}\left(\pi_{\mathrm{u}} 2 \mathrm{p}\right)^{4}\left(\sigma_{\mathrm{g}} 2 \mathrm{p}\right)^{2}$ fills the $\mathrm{K}$ vacancy with simultaneous emission of a second electron (Auger electron) of the same configuration. Because the $\mathrm{N}_{2}$ molecule has only closed orbitals in the ground state (1), the states of the $\mathrm{N}_{2}{ }^{2+}$ molecular ion are given by the states of the following 2-hole configurations:

$$
\begin{aligned}
& \left(\sigma_{\mathrm{g}} 2 \mathrm{p}\right)^{-2} \mathrm{i}^{1} \Sigma_{\mathrm{g}}{ }^{+}, \\
& \left(\pi_{\mathrm{u}} 2 \mathrm{p}\right)^{-1}\left(\sigma_{\mathrm{g}} 2 \mathrm{p}\right)^{-1}:{ }^{1} \Pi_{\mathrm{u}},{ }^{3} \Pi_{\mathrm{u}} \text {, } \\
& \left(\pi_{\mathrm{u}} 2 \mathrm{p}\right)^{-2}:{ }^{1} \Sigma_{\mathrm{g}}{ }^{+},{ }^{3} \Sigma_{\mathrm{g}}{ }^{-},{ }^{1} \Delta_{\mathrm{g}}, \\
& \left(\sigma_{\mathrm{u}} 2 \mathrm{~s}\right)^{-1}\left(\sigma_{\mathrm{g}} 2 \mathrm{p}\right)^{-1}:^{1} \Sigma_{\mathrm{u}}{ }^{+},{ }^{3} \Sigma_{\mathrm{u}}^{+}, \\
& \left(\sigma_{\mathrm{u}} 2 \mathrm{~s}\right)^{-1}\left(\pi_{\mathrm{u}} 2 \mathrm{p}\right)^{-1}:{ }^{1} \Pi_{\mathrm{g}},{ }^{3} \Pi_{\mathrm{g}} \text {, } \\
& \left(\sigma_{\mathrm{u}} 2 \mathrm{~s}\right)^{-2}:^{1} \Sigma_{\mathrm{g}}{ }^{+} \text {. } \\
& \left(\sigma_{\mathrm{g}} 2 \mathrm{~s}\right)^{-1}\left(\sigma_{\mathrm{g}} 2 \mathrm{p}\right)^{-1}:{ }^{1} \sum_{\mathrm{g}}{ }^{+},{ }^{3} \Sigma_{\mathrm{g}}{ }^{+}, \\
& \left(\sigma_{\mathrm{g}} 2 \mathrm{~s}\right)^{-1}\left(\pi_{\mathrm{u}} 2 \mathrm{p}\right)^{-1}:{ }^{1} \Pi_{\mathrm{u}},{ }^{3} \Pi_{\mathrm{u}} \text {, } \\
& \left(\sigma_{\mathrm{g}} 2 \mathrm{~s}\right)^{-1}\left(\sigma_{\mathrm{u}} 2 \mathrm{p}\right)^{-1}:{ }^{1} \Sigma_{\mathrm{u}}{ }^{+},{ }^{3} \Sigma_{\mathrm{u}}{ }^{+} \text {. } \\
& \left(\sigma_{\mathrm{g}} 2 \mathrm{~s}\right)^{-2}^{1} \Sigma_{\mathrm{g}}{ }^{+} \text {. }
\end{aligned}
$$

\begin{tabular}{|c|c|c|}
\hline Photoelect & spectroscopy & Absorption spectroscopy \\
\hline $412 \pm 1^{a}$ & $409 \pm 0.4_{b}$ & $409.5 \pm 0.1^{c}$ \\
\hline
\end{tabular}

The energy of $\mathrm{K}$ Auger electrons of transistion $k$ is given by

$$
E_{k}(\text { Auger })=E(\mathrm{~K})-E_{k}\left(\mathrm{~N}_{2}{ }^{2+}\right) .
$$

If the binding energy $E(\mathrm{~K})$ is known (see Table 1 ), then the energies $E_{k}$ (Auger) of the $\mathrm{K}$ Auger lines determine directly the unknown energies $E_{k}\left(\mathrm{~N}_{2}{ }^{2+}\right)$.

Table 1. Binding energy, $E(\mathrm{~K})$, of $\mathrm{K}$ electron in $\mathrm{N}_{2}(\mathrm{eV})$. ${ }^{a}$ Private communication by M. O. Krause, Oak Ridge Natl. Laboratories, 1968; ${ }^{\mathrm{b}}$ Private communication by K. HAMrIN, Institute of Physics, University of Uppsala, 1968; ${ }^{\mathrm{c}}$ Ref. ${ }^{15}$.

The final state $f$ of the molecule, given by $(2 \mathrm{a})$, (2b) and (2c), which can be arrived at by an Auger transition depends on the selection rules for the perturbation matrix element between the initial and final states. The initial state $\mathrm{i}$ is given by one of the following 2 -hole configurations

or

$$
\begin{aligned}
& \left(\sigma_{\mathrm{g}} \mathrm{ls}\right)^{-1},{ }^{2} \Sigma_{\mathrm{g}}+\left(E, l^{\prime}\right)^{-1} \\
& \left(\sigma_{\mathrm{u}} \mathrm{ls}\right)^{-1},{ }^{2} \Sigma_{\mathrm{u}}{ }^{+}\left(E, l^{\prime}\right)^{-1} .
\end{aligned}
$$

Here $\left(\sigma_{\mathrm{g}} 1 \mathrm{~s}\right)^{-1},{ }^{2} \Sigma_{\mathrm{g}}{ }^{+}$and $\left(\sigma_{\mathrm{u}} \mathrm{ls}\right)^{-1},{ }^{2} \Sigma_{\mathrm{u}}{ }^{+}$refer to the initial $K$ shell vacancy in the molecule while

10 R. W. Fink, R. C. Jopson, Hans Mark, and C. D. Swift, Rev. Mod. Phys. 38, 513 [1966].

11a See e. g. G. Herzberg, Spectra of Diatomic Molecules, $2^{\text {nd }}$ ed., p. 405 ff., D. van Nostrand Co., Inc., Princeton, N. J., 1966.
$\left(E, l^{\prime}\right)^{-1}$ refers to the hole in the continuum which is to become filled by the Auger electron with energy $E$ and orbital angular momentum quantum number $l^{\prime}$.

In molecules several perturbations may cause Auger transitions ${ }^{11 a}$. The following selection rules for these perturbations have been derived by KRONIG ${ }^{11 b}$ :

a) Regardless of the coupling scheme total angular momentum $J$ must be conserved: $J_{\mathrm{f}}=J_{\mathrm{i}}$.

b) There is no change of the symmetry property + or $-:+\leftarrow \mid \rightarrow-$.

c) In the case of homonuclear molecules only transitions $\mathrm{u} \rightarrow \mathrm{u}$ and $\mathrm{g} \rightarrow \mathrm{g}$ are allowed.

d) In Hund's cases (a) and (b) of coupling there must be in addition: $S_{\mathrm{f}}=S_{\mathrm{i}}$ and $\Lambda_{\mathrm{f}}=\Lambda_{\mathrm{i}}, \Lambda_{\mathrm{i}} \pm \mathrm{l}$. Here $S$ and $\Lambda$ refer to the total spin and total orbital angular momentum of electronic motion respectively.

From these selection rules it follows that Auger transitions from an initial state given by either the one or the other of the configurations of (4) to all the final states of $(2 \mathrm{a}),(2 \mathrm{~b})$ and $(2 \mathrm{c})$ are allowed.

The energies $E_{k}\left(\mathrm{~N}_{2}{ }^{2+}\right)$ determined by Eq. (3) need some further explanation. For this reason the potential energy curves of the ground state of $\mathrm{N}_{2}$, the excited state of the $\mathrm{N}_{2}{ }^{\mathrm{K}+}$ molecular ion and the states of the $\mathrm{N}_{2}{ }^{2+}$ molecular ion are plotted in Fig. 1 . The potential energy curves of $\mathrm{N}_{2}{ }^{2+}$ have been determined by the method of HURLEY and MASLEN ${ }^{8}$ by means of the following equation (energies are given in $\mathrm{eV}$, distances in $\AA$ ) :

$$
\begin{gathered}
U(R)=D_{0}\left(\mathrm{~N}_{2}\right)+2 \cdot I(\mathrm{~N})+E_{\mathrm{A}}+14.399 / R \\
-t^{2} D_{\mathrm{e}}\left(\mathrm{C}_{2}\right)\left[1-\left\{1-\exp \left[-\beta\left(t R-R_{\mathrm{e}}\right)\right]\right\}^{2}\right] .
\end{gathered}
$$

Eq. (5) follows from Fig. 2 and Eq. (5.1) of ref. ${ }^{8}$. The scale factor $t$ has been calculated by Eq. (3) of ref. ${ }^{9}$ and $\beta$ is given by

$$
\beta=\left(2 \pi^{2} \mu c / D_{\mathrm{e}} h\right)^{1 / 2} \omega_{\mathrm{e}} .
$$

The values of the constants $D_{\mathrm{e}}, \omega_{\mathrm{e}}$ and $R_{\mathrm{e}}$ of the different states of $\mathrm{C}_{2}$ have been taken from BALLIK and RAMSEY ${ }^{12}$ and their dissociation limits from Read and VAnderslice ${ }^{13}$ and Fougere and

11b R. DE L. Kronig, Z. Phys. 50, 347 [1928].

12 E. A. Ballik and D. A. Ramsay, Astrophys. J. 137, 84 [1963].

13 S. H. Read and J. T. Vanderslice, J. Chem. Phys. 36, 2366 [1962]. 


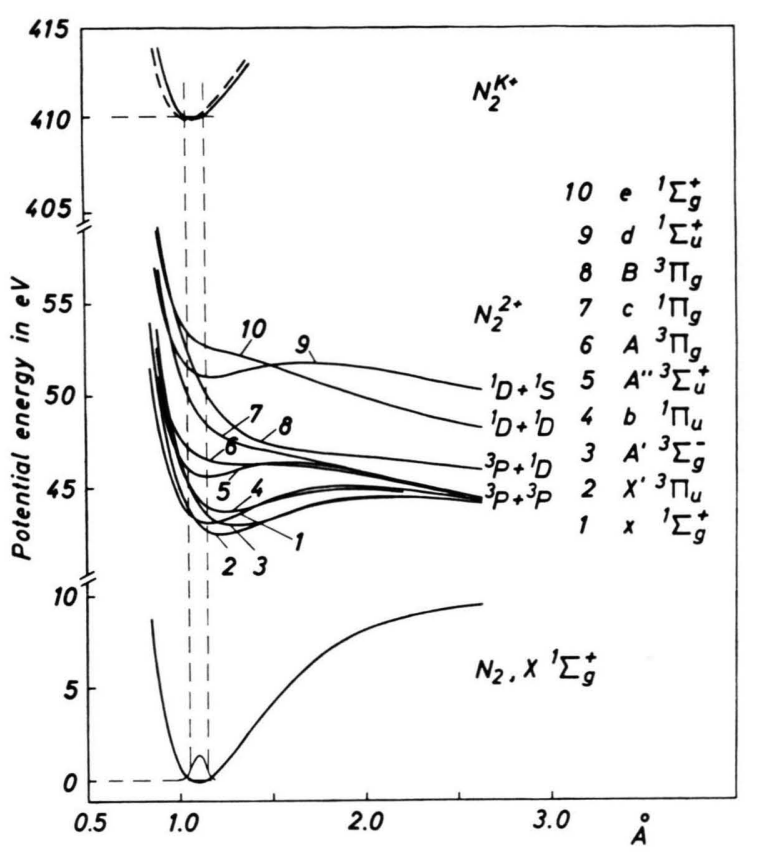

Fig. 1. Potential energy curves of the ground state of $\mathrm{N}_{2}$, the excited state of the $\mathrm{N}_{2} \mathrm{~K}^{+}$molecular ion and the states of the $\mathrm{N}_{2}{ }^{2+}$ ion. The designation of the $\mathrm{N}_{2}{ }^{2+}$ states is exactly analogous to that used for the isoelectronic molecule $\mathrm{C}_{2}$ (see Fougere and Nesbet ${ }^{14}$ ). For the $\mathrm{N}_{2} \mathrm{~K}^{+}$state two potential curves are shown:

Dashed line: $\quad R_{\mathrm{e}}\left(\mathrm{N}_{2} \mathrm{~K}^{+}\right)=R_{\mathrm{e}}\left(\mathrm{NO}^{+}, \mathrm{X}^{1} \Sigma^{+}\right)=1.062 \AA$. Solid line: $\quad R_{\mathrm{e}}\left(\mathrm{N}_{2} \mathrm{~K}^{+}\right)=R_{\mathrm{e}}\left(\mathrm{N}_{2}, \mathrm{X}^{1} \sum_{\mathrm{g}^{+}}\right)=1.097 \AA$.

The vertical dashed lines determine the Franck-Condon region where the Auger transitions are assumed to take place.

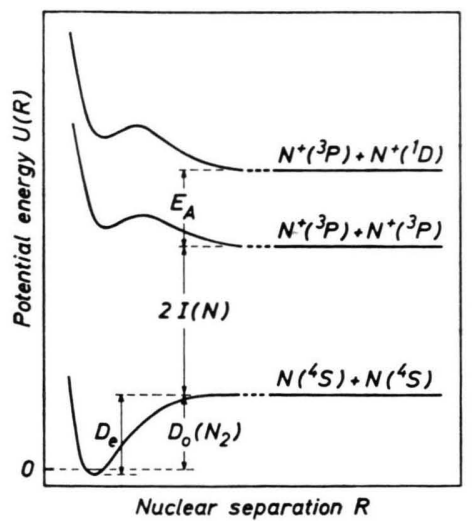

Fig. 2. Relationship of energies for the $\mathrm{N}_{2}{ }^{2+}$ molecular ion.

NeSBET ${ }^{14}$. The designation of the states of $\mathrm{N}_{2}{ }^{2+}$ used in Fig. 1 and throughout this paper is exactly analogous to that used for the isoelectronic molecule $\mathrm{C}_{2}$ by Fougere and Nesbet ${ }^{14}$.

14 P. F. Fougere and R. K. Nesbet, J. Chem. Phys. 44, 285 [1966].
In the scheme of potential curves an ionization in the $\mathrm{K}$ shell is given by a vertical transition within the Franck-Condon region from the level $v^{\prime \prime}=0$ of the ground state of $\mathrm{N}_{2}$ to one of the vibrational levels $v^{\prime}$ of the $\left(\sigma_{\mathrm{g}} l \mathrm{~s}\right)^{-1},{ }^{2} \Sigma_{\mathrm{g}}{ }^{+}$or $\left(\sigma_{\mathrm{u}} \mathrm{ls}\right)^{-1},{ }^{2} \Sigma_{\mathrm{u}}{ }^{+}$state. The potential energy curves of those states are not known. With NAKamura et al. ${ }^{15}$ it seems reasonable to assume the state of the $\mathrm{N}_{2}{ }^{\mathrm{K}+}$ molecular ion to be similar to the ground state $\mathrm{X}^{1} \Sigma^{+}$of $\mathrm{NO}^{+}$. Therefore we have used the relation $R_{\mathrm{e}}\left(\mathrm{N}_{2}{ }^{\mathrm{K}+}\right)=R_{\mathrm{e}}\left(\mathrm{NO}^{+}, \mathrm{X}^{1} \Sigma^{+}\right)=1.062 \AA$ for the potential curve of $\mathrm{N}_{2}{ }^{\mathrm{K}+}$ (dashed curve in Fig. 1). This value of $R_{\mathrm{e}}$ is close to $R_{\mathrm{e}}\left(\mathrm{N}_{2}, \mathrm{X}^{1} \Sigma_{\mathrm{g}}{ }^{+}\right)=1.097 \AA$. From this on expects a strong $0-0$ transition and a decreasing probability for $v^{\prime \prime}=0 \rightarrow v^{\prime}>0$ transitions.

The excited state $\mathrm{N}_{2}{ }^{\mathrm{K}+}$ decays with a mean life time of several $10^{-14} \mathrm{sec}$ via a vertical transition to one of the $\mathrm{N}_{2}{ }^{2+}$ states. These states are either bound and have discrete vibrational structure or are repulsive and have a continuous energy spectrum. Because the $\mathrm{N}_{2}{ }^{\mathrm{K}+}$ state is mostly populated in the level $v^{\prime}=0$ and $R_{\mathrm{e}}\left(\mathrm{N}_{2}{ }^{\mathrm{K}+}\right)$ does not differ strongly from $R_{\mathrm{e}}\left(\mathrm{N}_{2}, \mathrm{X}^{1} \Sigma_{\mathrm{g}}{ }^{+}\right)$, the Franck-Condon region for Auger transitions was assumed to be identical with that of the $v^{\prime \prime}=0$ level of $\mathrm{N}_{2}, \mathrm{X}^{1} \Sigma_{\mathrm{g}}{ }^{+}$(dashed vertical lines in Fig. 1).

Due to the short life time of the $\mathrm{N}_{2}{ }^{\mathrm{K}+}$ state of several $10^{-14} \mathrm{sec}$ the level widths are of the order of $0.10-0.15 \mathrm{eV}$. From this one would expect vibrational structure of Auger lines in the following cases: a) The $\mathrm{N}_{2}{ }^{\mathrm{K}+}$ state is populated practically only in one level $v^{\prime}$. Then the spacing of final levels $v^{\prime \prime}$ of the $\mathrm{N}_{2}{ }^{2+}$ states must be $\gtrsim 0.10-0.15 \mathrm{eV}$. b) The $\mathrm{N}_{2}{ }^{\mathrm{K}+}$ state is populated in more than one level. Then the spacing of $v^{\prime}$ and $v^{\prime \prime}$ levels should be $\gtrsim 0.10-0.15 \mathrm{eV}$ and approximately equal. No vibrational structure will be observed in cases where the final state dissociates.

One additional interesting feature of Auger electron spectroscopy of molecules should be mentioned. Heteronuclear molecules, e. g. CO, can be investigated via the $\mathrm{K}$ Auger spectrum of $\mathrm{C}$ or the $\mathrm{K}$ Auger spectrum of $\mathrm{O}$. In both cases the final states of $\mathrm{CO}^{2+}$ are identical, but the initial states $\mathrm{C}^{\mathrm{K}+} \mathrm{O}$ and $\mathrm{CO}^{\mathrm{K}+}$ may differ in their potential energy

15 M. Nakamura, M. Sasanuma, S. Sato, M. Watanabe, H. Yamashita, Y. Iguchi, A. Ejiri, S. Nakai, S. Yamaguchi, T. Sagawa, Y. Nakai, and T. Oshio, Phys. Rev. 178, 80 [1969]. 
curves thus giving different Auger spectra. We have indeed found quite different Auger spectra in the case of $\mathrm{CO}$. The results of that investigation will be given in a further publication.

\section{Apparatus}

The apparatus used in this investigation has been described earlier ${ }^{16}$. Therefore only some details which are characteristic for this investigation will be given here.

The ionization in the $\mathrm{K}$ shell of $\mathrm{N}_{2}$ was caused by electron impact, the beam current and energy of primary electrons were $300 \mu \mathrm{A}$ and $6000 \mathrm{eV}$ respectively. The pressure of the gaseous target $\mathrm{N}_{2}$ was about $5 \cdot 10^{-3}$ Torr. The Auger electrons were analyzed by means of an electrostatic cylindrical mirror analyzer with an energy resolution of $0.16 \%$. Sixty five $\mathrm{K}$ Auger spectra were recorded and added automatically with a 1024 channel multiscaler by applying a dc biased sawtooth voltage, with a repetition rate of one cycle per $16 \mathrm{~min}$, to the spectrometer and storing the counts in the memory of the multiscaler synchronized with the sawtooth.

The $\mathrm{K}$ Auger lines of $\mathrm{N}_{2}$ were calibrated on an absolute scale with the known energies of the KLL transitions of neon ${ }^{16}$ and $\mathrm{L}_{2,3} \mathrm{MM}$ transitions of argon ${ }^{17}$. For this calibration gas mixtures of $\mathrm{N}_{2}$-neon and $\mathrm{N}_{2}$-argon were used.

\section{Results and Discussion}

Figure 3 shows the $\mathrm{K}$ Auger spectrum of $\mathrm{N}_{2}$. No correction for the dispersion of the spectrometer and the scattering losses of Auger electrons along the path from the target to the detector were applied to the spectrum because we were only interested in the energies of Auger electrons.
The maximum energy of the $\mathrm{K}$ Auger transitions of $\mathrm{N}_{2}$ can be calculated by Eq. (3) to be (366.3 \pm $0.5) \mathrm{eV}$. Here we have used $E(\mathrm{~K})=(409.8 \pm 0.4) \mathrm{eV}$ of Table 1 and the minimum appearance potential of $\mathrm{N}_{2}{ }^{2+}$ of $(43.5 \pm 0.3) \mathrm{eV}^{4}$. We prefer this value of $E(\mathrm{~K})$, because the photoelectron method measures the binding energy more directly than the method used by NAKAmura et al. ${ }^{15}$ (analysis of fine structure near the absorption edge). We determined the energy of maximum $\alpha$ in Fig. 3 to be $(366.5 \pm 0.5)$ $\mathrm{eV}$, thus the maximum $\alpha$ is due to Auger transitions with the ground state of $\mathrm{N}_{2}{ }^{2+}$ as the final state.

The spectrum of Fig. 3 decomposes clearly into three groups which are marked by the hatched regions $\mathrm{A}$ and $\mathrm{B}$ and the maximum $\mathrm{C}$. These three groups correspond to the final states given in $(2 \mathrm{a})$, $(2 \mathrm{~b})$ and $(2 \mathrm{c})$. From the potential energy curves of Fig. 1 it was possible to assign definite final states of the $\mathrm{N}_{2}{ }^{2+}$ molecular ion to those Auger transitions of group $\mathrm{A}$ which appear as distinct maxima.

In Fig. 4 the Auger group $\mathrm{A}$ is shown on an enlarged scale. The hatched regions above the energy axis correspond to the energy regions of the potential curves of Fig. 1 within the Franck-Condon region. There is indeed good agreement between these predicted energy regions and the various Auger maxima. As a consequence of this we were able to assign definite states of $\mathrm{N}_{2}{ }^{2+}$ to the maxima $\alpha, \beta, \gamma, \delta, \varepsilon$, and $\varphi$ of Fig. 4 (see Table 2). The experimental energies, given in Table 2, correspond to the maxima of the Auger lines and are relative to the maximum $\alpha$. In Table 2 theoretical relative vertical ionization energies are also listed. The first

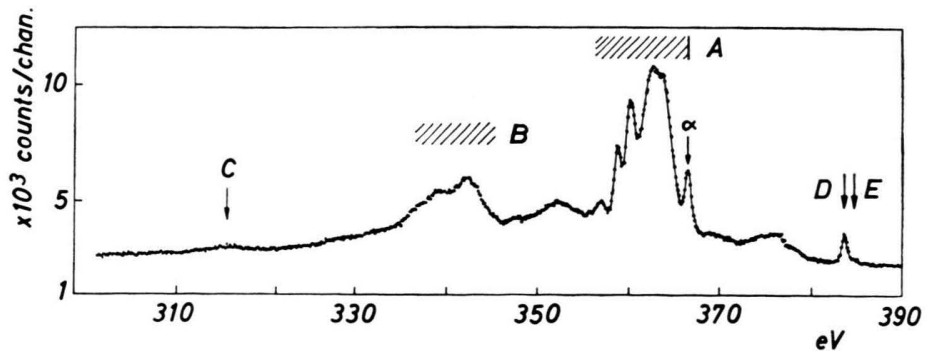

Fig. 3. K Auger spectrum of $\mathrm{N}_{2}$.

Fig. 4. High energy part of the $\mathrm{K}$ Auger spectrum of $\mathrm{N}_{2}$. The numbering of the energy regions correspond to that identifying the states of $\mathrm{N}_{2}{ }^{2+}$ in Fig. 1 .

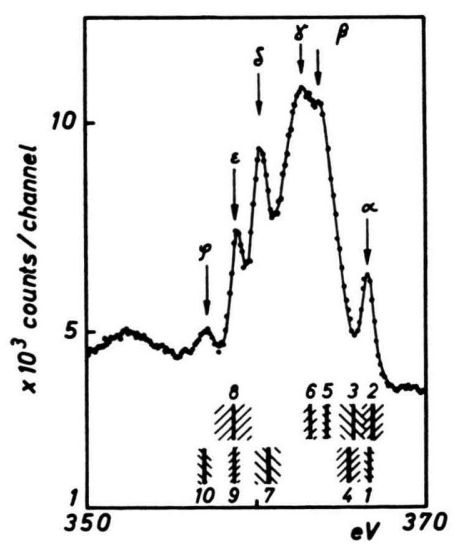

16 H. Körber and W. Mehlhorn, Z. Phys. 191, 217 [1966]. ${ }^{17}$ D. Stalherm and W. Mehlhorn, Z. Phys. 217, 294 [1968]. 
set has been deduced from Fig. 1 and the second has been taken from HURLEY ${ }^{9}$. In both cases they correspond to ionizing transitions at $R_{\mathrm{e}}\left(\mathrm{N}_{2}, \mathrm{X}^{1} \Sigma_{\mathrm{g}}{ }^{+}\right)=$ $1.097 \AA$. Although HURLeY ${ }^{9}$ calculated the potential energy curves by an equation which was slightly different from Eq. (5), both sets of theoretical values agree very well.

\begin{tabular}{ccccc}
\hline & \multicolumn{2}{c}{ Experiment } & \multicolumn{2}{c}{ Theory } \\
Auger & UV & This & HUR- \\
State & spectroscopy & spectro- & This \\
& This work & $\begin{array}{c}\text { scopy } \\
\text { ref. }{ }^{5}, 6\end{array}$ & work & LEY \\
& & & \\
\hline
\end{tabular}

\begin{tabular}{|c|c|c|c|c|c|}
\hline \multicolumn{6}{|c|}{ Electron configurations $(2 \mathrm{a})$} \\
\hline $\mathrm{x}$ & $1 \sum_{\mathrm{g}}{ }^{+}$ & $(\alpha)$ & 0 & $\begin{array}{ll}0 & { }_{-0.1}^{+0.4}\end{array}$ & 0 \\
\hline $\mathrm{X}^{\prime}$ & $3 \Pi_{\mathrm{u}}^{\mathrm{s}}$ & & & $-0.1_{-0.8}^{+0.8}$ & -0.1 \\
\hline $\mathrm{A}^{\prime}$ & $3 \sum_{\mathrm{g}}^{-}$ & & & $1.0_{-0,6}^{+1.0}$ & 1.04 \\
\hline $\mathrm{b}$ & $1 \Pi_{\mathrm{u}}^{\circ}$ & & & $1.3_{-0.5}^{+0.8}$ & 1.26 \\
\hline $\mathrm{A}^{\prime}$ & ${ }^{3} \Sigma_{u^{+}}+$ & $2.9 \pm 0.4(\beta)$ & & $2.5_{-0.1}^{+0.3}$ & - \\
\hline A & ${ }^{3} \Pi_{\mathrm{g}}$ & $3.9 \pm 0.4(\gamma)$ & & $3.5_{-0.2}^{+0.4}$ & 3.41 \\
\hline c & ${ }^{1} \Pi_{\mathrm{g}}^{\circ}$ & $6.4 \pm 0.3(\delta)$ & & $5.9_{-0.6}^{+1.0}$ & 5.91 \\
\hline B & ${ }^{3} \Pi_{\mathrm{g}}$ & & & $7.9_{-1,0}^{+1.2}$ & - \\
\hline d & $1 \Sigma_{\mathrm{u}^{+}}$ & $7.9 \pm 0.25(\varepsilon)$ & 7.80 & $7.9_{-0.2}^{+0.4}$ & 7.99 \\
\hline e & ${ }^{1} \sum_{\mathrm{g}^{+}}$ & $9.5 \pm 0.25(\varphi)$ & & $9.8_{-0,3}^{+0.5}$ & - \\
\hline & $1 \Sigma_{\mathrm{g}}{ }^{+}$ & $53.0 \pm 1.0(\mathrm{C})$ & & & \\
\hline
\end{tabular}

Table 2. Relative vertical energies of the $\mathrm{N}_{2}{ }^{2+}$ molecular ion in $\mathrm{eV}$. The letters in parenthesis refer to the Auger maxima of Fig. 3 and $4 .-{ }^{a}$ The notation of the states is exactly analogous to that used for the isoelectronic molecule $\mathrm{C}_{2}$ by FouGERE and NESBET ${ }^{14}$; ${ }^{\mathrm{b}}$ The errors correspond to the FranckCondon region (dashed lines) of Fig. 1.

We believe that the maximum $\alpha$ corresponds mainly to $\mathrm{x}^{1} \Sigma_{\mathrm{g}}{ }^{+}$rather than $\mathrm{X}^{\prime}{ }^{3} \Pi_{\mathrm{u}}$ because the small experimental width of the line $\alpha$ agrees with the predicted line width by the Franck-Condon region (see hatched region 1 in Fig. 4). From the broader energy region of Auger transitions to $\mathrm{X}^{\prime}{ }^{3} \Pi_{\mathrm{u}}$ (hatched region 2 in Fig. 4) we expect a broad maximum which is masked by the maxima $\alpha$, $\beta$ and $\gamma$. For the same reason the maximum $\varepsilon$ is believed to correspond to $\mathrm{d}^{1} \Sigma_{\mathrm{u}}{ }^{+}$rather than $\mathrm{B}^{3} \Pi_{\mathrm{g}}$. Also the transitions to the states $\mathrm{A}^{\prime}{ }^{3} \Sigma_{\mathrm{g}}{ }^{-}$and $\mathrm{b}^{1} \Pi_{\mathrm{u}}$ are expected to give rather broad Auger lines. This and the possibility to have small relative intensity may have prevented their observation as distinct maxima.

The agreement between the relative energies of maximum $\varepsilon$ and the $\mathrm{d}^{1} \Sigma_{\mathrm{u}}{ }^{+}$state, found by CARROLL $^{5,6}$, is excellent. The energy required to ionize the $\mathrm{N}_{2}$ molecule twofold in the $\left(\sigma_{\mathrm{g}} 2 \mathrm{~s}\right)$ orbital has been determined via the Auger line $\mathrm{C}$ to be $(96.5 \pm 1.0) \mathrm{eV}$.
The Auger line $\mathrm{D}$ at $(383.7 \pm 0$. $) \mathrm{eV}$ in Fig. 3 is most probably due to the following autoionizing transitions leading to $\mathrm{N}_{2}^{+}$:

$$
\left.\begin{array}{l}
\left(\sigma_{\mathrm{u}} 1 \mathrm{~s}\right)^{-1}\left(\pi_{\mathrm{g}} 2 \mathrm{p}\right)^{1},{ }^{1} \Pi_{\mathrm{u}} \\
\left(\sigma_{\mathrm{g}} 1 \mathrm{~s}\right)^{-1}\left(\pi_{\mathrm{g}} 2 \mathrm{p}\right)^{1},{ }^{1} \Pi_{\mathrm{g}}
\end{array}\right\} \rightarrow \begin{aligned}
& \left(\pi_{\mathrm{u}} 2 \mathrm{p}\right)^{-1}, \mathrm{~A}^{2} \Pi_{\mathrm{u}} \\
& \text { + Auger electron. }
\end{aligned}
$$

NAKAMURA et al. ${ }^{15}$, using synchrotron radiation, have measured the autoionizing state $\left(\sigma_{\mathrm{u}} l \mathrm{~s}\right)^{-1}$ $\left(\pi_{\mathrm{g}} 2 \mathrm{p}\right)^{1},{ }^{1} \Pi_{\mathrm{u}}$, of the $\mathrm{N}_{2}$ molecule as a strong and broad band in the absorption spectrum. Earlier measurements of the fine structure near the $\mathrm{K}$ absorption edge of gaseous $\mathrm{N}_{2}$ by PRINS ${ }^{18}$ and MAGNUSSON ${ }^{19}$ have also shown this strong resonance absorption but with less instrumental resolution. The energy of the level $v^{\prime}=0$ of this autoionizing state is given by NAKAMURA et al. ${ }^{15}$ as $(400.24 \pm$ $0.1) \mathrm{eV}$. The energy of the level $v^{\prime \prime}=0$ of $\mathrm{N}_{2}^{+}$, $\mathrm{A}^{2} \Pi_{\mathrm{u}}$ is $16.74 \mathrm{eV}$. Therefore the energy of the $0-0$ Auger transition of (7) is $(383.5 \pm 0.1) \mathrm{eV}$. From the broad absorption band, measured by NAKamura et al., it follows that higher vibrational levels (up to $v^{\prime}=4$ or 5 ) of the autoionizing state are excited with almost equal probability. On the other hand the half width of the Auger line D is about $0.75 \mathrm{eV}$, where about $0.6 \mathrm{eV}$ is due to the instrumental width. So the natural width of the line $\mathrm{D}$ is quite small, being about $0.4-0.5 \mathrm{eV}$. This would demand that only transitions with $\Delta v=$ 0 and \pm 1 will occur with considerable intensity.

The small maximum E in Fig. 3 is probably due to the autoionizing transitions

$$
\left.\begin{array}{l}
\left(\sigma_{\mathrm{u}} 1 \mathrm{~s}\right)^{-1}\left(\pi_{\mathrm{g}} 2 \mathrm{p}\right)^{1},{ }^{1} \Pi_{\mathrm{u}} \\
\left(\sigma_{\mathrm{g}} 1 \mathrm{~s}\right)^{-1}\left(\pi_{\mathrm{g}} 2 \mathrm{p}\right)^{1},{ }^{1} \Pi_{\mathrm{g}}
\end{array}\right\} \rightarrow \begin{aligned}
& \left(\sigma_{\mathrm{g}} 2 \mathrm{p}\right)^{-1}, \mathrm{X}^{2} \Sigma_{\mathrm{g}}{ }^{+} \\
& + \text {Auger electron. }
\end{aligned}
$$

The structure of the Auger spectrum around $376 \mathrm{eV}$ is supposed to result from autoionizing transitions leading to highly excited electronic states of $\mathrm{N}_{2}^{+}$. The broad maximum at about $352 \mathrm{eV}$ in Fig. 3 has not yet been identified. One possible explanation is that this maximum is due to Auger satellite transitions following the simultaneous ionization of the $\mathrm{N}_{2}$ molecule in the $\mathrm{K}$ shell and the outer shell by electron impact. This would be exactly analogous to the Auger satellite lines found recently in neon ${ }^{16}$ and $\operatorname{argon}{ }^{17}$.

18 J. A. Prins, Physica, Haag 1, 1174 [1934].

19 T. Magnusson, Nova Acta Reg. Soc. Sci. Upsal. 11, No. 3 [1938]. 
In this investigation no fine structure of the Auger lines due to vibrational levels of $\mathrm{N}_{2}{ }^{\mathrm{K}+}$ and $\mathrm{N}_{2}{ }^{2+}$ has been found. The main reason for this is the instrumental width of about $0.6 \mathrm{eV}$ at energies of the Auger group A. In order to detect any vibrational structure the resolution of the spectrometer should be increased at least by a factor of two.
The authors are indebted to Prof. Dr. E. HUSTER for his continuing interest in this investigation, to Prof. Dr. O. Osberghaus, and Dr. Brehm for discussions at an earlier stage of this work and to the Deutsche Forschungsgemeinschaft for financial support.

\title{
On the Phonon and Polariton Spectrum of $\mathrm{LiJO}_{3}{ }^{*}$
}

\author{
R. Claus, H. W. SchrötTer, and H. H. Hacker \\ Sektion Physik der Universität München, Lehrstuhl Prof. BRANDMüLleR \\ and S. HAUSsüHL \\ Institut für Kristallographie der Universität Köln \\ (Z. Naturforsch. 24 a, 1733-1736 [1969] ; received 13 September 1969)
}

\begin{abstract}
Raman spectra of the polar $\mathrm{A}, \mathrm{E}_{1}$ and the non polar $\mathrm{E}_{2}$ species of $\mathrm{LiJO}_{3}$ are presented. The number of phonons expected by group theory has been calculated. LO-TO splitting of two $\mathrm{E}_{\mathbf{1}}$. phonons could be observed and the polariton associated with the $\mathrm{A}(\mathrm{z})$ phonon at $795 \mathrm{~cm}^{-1}$ has been recorded.
\end{abstract}

Since NATH and HaussüHL detected the strong second harmonic generation of a ruby laser in Lithtium Iodate ${ }^{1}$ and an extremely great piezoelectric longitudinal effect parallel to [001] was detected ${ }^{2}$, the $\mathrm{LiJO}_{3}$ crystal has become of great common interest. The present paper will deal with the vibrational species of the optical phonons observed by Raman scattering experiments.

\section{Theory}

$\mathrm{LiJO}_{3}$, which belongs to the crystal symmetry class $\mathrm{C}_{6}$, as could be shown three years ago ${ }^{3,4}$, has the Raman scattering tensors ${ }^{5}$

$\mathrm{A}(z)\left(\begin{array}{ccc}a & 0 & 0 \\ 0 & a & 0 \\ 0 & 0 & b\end{array}\right) ; \quad \mathrm{E}_{1}(x)\left(\begin{array}{lll}0 & 0 & c \\ 0 & 0 & d \\ c & d & 0\end{array}\right) ;$

* This work was partly reported at the International Conference on Raman Spectroscopy, Ottawa, August 1969, and the Conference EUCHEM, Jouy en Josas, September 1969.

Reprint requests to Dr. H. W. SchrötTER, D-8000 München 13, Amalienstraße 54.

1 G. Nath and S. HaussüHL, Phys. Letters 29 A, 91 [1969].

$$
\begin{gathered}
\mathrm{E}_{1}(y)\left(\begin{array}{rrr}
0 & 0 & -d \\
0 & 0 & c \\
-d & c & 0
\end{array}\right) ; \\
\mathrm{E}_{2}\left(\begin{array}{rrr}
f-e & -e \\
-e & -f & 0 \\
0 & 0 & 0
\end{array}\right) .
\end{gathered}
$$

The $E_{2}$ species are doubly degenerate unpolar modes while the $A$ and $E_{1}$ species are both infrared and Raman active. The $\mathrm{E}_{2}$ species can easily be observed separately using $x(y x) y$ scattering geometry, while the $A$ and $E_{1}$ species in general will mix. In order to find adequate scattering geometries for separation, one will have to examine the scattering efficiencies using the well-known formula for the scattering intensity of an uniaxial piezoelectric crystal, given by LoudoN ${ }^{5}$. Thus, using a phonon wave vector propagating in the $x y$-plane along the bisecting line of the $x$ and $y$ axes, the most general

2 S. HaussüHL, Phys. Status Solidi 29, K 159 [1968].

3 A. Rosenzweig and B. Morosin, Acta Cryst. 20, 758 [1966].

4 J. L. De Boer, F. van Bolhuis, R. Olthof-Hazekamp, and A. Vos, Acta Cryst. 21, 841 [1966].

5 R. Loudon, Advan. Phys. 13, 423 [1964]. 